\title{
DIREITO E ESPAÇO NO PROGRAMA “MINHA CASA, MINHA VIDA" EM JOÃO PESSOA
}

\section{LAW AND GEOGRAPHIC SPACE IN THE "MINHA CASA, MINHA VIDA" POLICY IN JOÃO PESSOA}

Recebimento em 30/04/2021

Aceito em 09/07/2021

\author{
Fernando Joaquim Ferreira Maia ${ }^{1}$ \\ Klivia Larissa Cardoso da Costa ${ }^{2}$
}

\section{RESUMO}

Trata-se de ensaio sobre a teoria das rugosidades de Milton Santos aplicada no espaço urbano de João Pessoa, tendo por objeto o programa "Minha Casa, Minha Vida (faixa 1)". Existe uma seletividade do solo urbano e da hipervalorização de espaços que não são acessados pela população de baixa e média renda de João Pessoa, em contradição com os objetivos e as diretrizes do plano diretor da cidade, que dispõem acerca do "uso socialmente justo da propriedade e do solo urbano". Ao se adotar as ideias de Milton Santos, propõe-se que o espaço seja definido como um conjunto indissociável de objetos e de sistemas de ações. Assim, pode-se reconhecer suas categorias analíticas internas, particularmente o espaço produzido, as rugosidades e as formasconteúdo. Pretende-se responder ao seguinte questionamento: "o programa "Minha Casa, Minha Vida (faixa 1)", em João Pessoa, se afasta da tendência histórica da periferização da população socialmente vulnerável? A partir deste problema, objetiva-se analisar, no município de João Pessoa - PB, o programa "Minha Casa, Minha Vida" faixa 1 (um)" e a sua conformação com a produção do espaço urbano nos principais conjuntos habitacionais do município. Parte-se da hipótese de que nos projetos implementados pela Companhia Estadual de Habitação Popular (CEHAP) existem discrepâncias na seleção dos locais a serem construíd os para moradias pelo mencionado programa governamental, particularmente na faixa 1 de habitação. Evidencia-se a contradição do que dispõe a legislação municipal, coadunando a análise acerca das rugosidad es que compõem a racionalidade espacial na ótica da globalização.

Palavras-chave: Direito à cidade. João Pessoa. Plano diretor. Habitação. Milton Santos.

\section{ABSTRACT}

This is an essay on the theory of roughness by Milton Santos, applied in the urban space of João Pessoa, with the object of the public policy "Minha Casa, Minha Vida (category 1)". There is a selectivity of urban land and overvaluation of spaces that are not accessed by the low and middle income population of João Pessoa, in contradiction with the objectives and guidelines of the city's master plan, which provide for the socially fair use of property and urban land ". When you adopt Milton Santos' ideas, it is proposed that space be defined as an inseparable set of objects and systems of actions. Thus, it is possible to register its internal analytical categories, especially the space produced, such as roughness and forms-content. Make an answer to the following question: "Is the program" Minha Casa, Minha Vida (category 1) "in João Pessoa close to the

${ }^{1}$ Professor Associado da Universidade Federal da Paraíba. Professor Permanente do Programa de PósGraduação em Ciências Jurídicas da Universidade Federal da Paraíba-PPGCJ/UFPB. Colaborador da Rede INCIT do Observatório das Metrópoles-Núcleo Paraíba. Ex-Professor Adjunto da Universidade Federal Rural de Pernambuco. Possui Doutoradoe Mestradoem Direito pela Universidade Federal de Pernambuco, Especialização em Direito Processual Civil pela mesma Universidade e Graduação em Direito pela Universidade Católica de Pernambuco.

${ }^{2}$ Bacharela em Direito pela Universidade Federal da Paraíba(UFPB), ex-aluna de iniciação científica. 


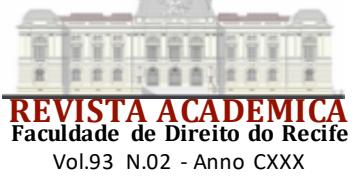

historical trend of peripheralization of the socially vulnerable population? Based on this problem, the objective is to analyze, in the municipality of João Pessoa - PB, the program "Minha Casa, Minha Vida" (category one) "and its conformation with the production of urban space in the main housing complexes in the municipality. It is based on the hypothesis that the projects implemented by the Companhia Estadual de Habitação Popular (CEHAP), there are differences in the selection of places to be built for housing by the public policy, especially in category one of housing. The contradiction in the municipality's rules on the subject is evident, demanding an analysis of the roughnesses that make up spatial rationality in the perspective of globalization.

Keywords: Right to the city. João Pessoa. Master plan. Housing. Milton Santos.

\section{INTRODUÇÃO}

Este artigo é fruto do plano de trabalho aprovado para o Programa de Iniciação Científica (Edital 01/2018/Propesq seleção de projetos de iniciação científica - 2018/2019), desenvolvido na Universidade Federal da Paraíba e parte das discussões do projeto de pesquisa "O direito à cidade a partir da crise do capitalismo e o seu impacto na discussão do processo de formação de gestores e planejadores urbanos" (UNIVERSIDADE FEDERALDA PARAÍBA, 2019).

Trata-se de um ensaio sobre a teoria das rugosidades de Milton Santos aplicada no espaço urbano de João Pessoa, tendo por objeto de análise o programa "Minha Casa, Minha Vida (faixa $1)^{\prime \prime}$.

A escolha por esta temática se deu por conta da seletividade do solo urbano e da hipervalorização de espaços que não são acessados pela população de baixa e média renda de João Pessoa em contradição com os objetivos e as diretrizes do plano diretor da cidade, que dispõem acerca do "uso socialmente justo da propriedade e do solo urbano".

A adoção do pensamento de Milton Santos sobre as rugosidades, como referencial teórico deste artigo, força a assunção da sua teoria social crítica como método. Santos (2017, p. 21) propõe que o espaço seja definido como um conjunto indissociável de objetos (que envolve as forças produtivas) e de sistemas de ações (que envolvem as relações de produção). A partir desta noção, pode-se reconhecer suas categorias analíticas internas, particularmente a paisagem, a configuração territorial, a divisão territorial do trabalho, o espaço produzido, as rugosidades e as formasconteúdo(SANTOS, 2017, p. 22). Paralelamente, propõe a racionalidade do espaço como conceito histórico atual e, ao mesmo tempo, fruto da emergência das redes e do processo de globalização. O conteúdo geográfico, a ordem mundial e a ordem local se incluem nesses conceitos constitutivos e operacionais (SANTOS, 2017, p. 22-23).

Será utilizado como instrumento de pesquisa as referências bibliográficas, sobre as quais se extrairão dados, para compreender o movimento de ocupação das áreas periféricas da cidade a partir da ordem do discurso estatal que, supõe-se, segue a lógica da "casa-mercadoria" nos moldes da acumulação do capital.

Pretende-se responder ao seguinte questionamento: "o programa "Minha Casa, Minha Vida (faixa 1)", enquanto política de habitação implantada no município de João Pessoa, afasta-se da tendência histórica da periferização da população socialmente vulnerável? A partir deste problema, o presente trabalho tem como objetivo analisar, no município de João Pessoa - PB, o programa intitulado "Minha Casa, Minha Vida" faixa 1 (um) e a conformação da produção do espaço urbano nos principais conjuntos habitacionais do município sob a perspectiva da teoria crítico-social de Milton Santos.

Desse modo, serão abordados o histórico e o fortalecimento dos projetos de habitação popular no contexto brasileiro, adentrando nas especificidades do município de João Pessoa - PB, de modo a melhor analisar o fenômeno da valorização imobiliária e a seletividade que os espaços 
urbanos foram submetidos. Posteriormente, analisar-se-á a conformação do Programa "Minha Casa, Minha Vida" (PMCMV), com sua legislação pertinente e as diretrizes que a orienta, conferindo enfoque à faixa I de renda, objeto do presente estudo. Já o terceiro ponto do trabalho busca relacionar a problemática da seletividade dos espaços com a teoria das rugosidades de Milton Santos, visando investigar se existe segregação de determinados segmentos sociais em nos locais selecionados pelo projeto governamental. Por fim, será feita a análise da lista de habitações da Companhia de Habitação Popular (CEHAP) da cidade de João Pessoa - PB a fim de melhor compreender os espaços onde são construídas as casas do PMCMV, faixa I.

Por fim, sustenta-se a hipótese de que, a partir da análise dos projetos implementados pela Companhia Estadual de Habitação Popular (CEHAP), existem discrepâncias na seleção dos locais a serem construídos para moradias pelo mencionado programa governamental, particularmente quando se refere à faixa 1 de habitação, que, conforme a legislação, é garantida àqueles que possuem renda bruta de até $\mathrm{R} \$ 1.600,00$ (mil e seiscentos reais). Isto pode ser uma evidência da contradição da legislação municipal e coaduna a análise de Milton Santos acerca das rugosidades que compõem a racionalidade espacial na ótica da globalização.

\section{O HISTÓRICO DA HABITAÇÃO POPULAR NA CIDADE DE JOÃO PESSOA: O PROCESSO DE VALORIZAÇÃO DO TERRITÓRIO E O RETRATO POPULACIONAL}

A análise da questão habitacional envolve a problemática da luta pelo direito à moradia e pela dignidade da pessoa humana. A Constituição Federal de 1988 coloca a habitação entre os direitos sociais, estes sendo aqueles notadamente passíveis da ação da intervenção do Estado como ente garantidor da plena eficácia da disposição legal. Neste sentido, o art. 23, IV da Constituição trata da competência comum de tod os os entes federativos em "promover programas de construção de moradias e a melhoria das condições habitacionais e de saneamento básico".

A produção de espaço se dá a partir da conciliação dos fatores econômicos, referentes ao preço do solo, com a valorização do terreno utilizado. Essa dualidade promove o antagonismo entre os interesses de capital e os direitos previstos pelo ordenamento jurídico que fundam a problemática da moradia na contemporaneidade.

Tal questão não é diferente diante da reflexão acerca da construção do espaço residencial e urbano na cidade de João Pessoa-PB. A produção de habitações populares adstritas às áreas periféricas do município comprova os interesses que giram em torno de tais conjuntos, promovendo clara "seleção" dos espaços de pobreza e de marginalização. Assim, a iniciativa de regulação e de promoção de moradias, a partir de subsídios e sorteios governamentais, em tese, garante a legalidade estrita no sentido de atender à solicitação constitucional de garantia do espaço residencial, mas peca ao tornar questão social a periferização dos grupos sociais a que são destinados essas unidades habitacionais.

Seguindo o percurso de todas as cidades brasileiras, o município de João Pessoa começa a montar seu esboço urbano no início do século XX. A construção da Avenida Epitácio Pessoa é um fato emblemático que ilustra esse processo, pois tal "deságue" promoveu a instalação de grupos familiares em seu entorno, a exemplo do Bairro dos Estados, dando início ao recorte de classe existente nos bairros da zona norte e zona sul e sudeste, sendo este processo intensificado a partir do fomento do Banco Nacional de Habitação (BNH).

A partir da década de 1930 houve a criação do Instituto de Aposentadoria e Pensões (IAPS), que atendia de modo análogo ao Fundo de Garantia por Tempo de Serviço (FGTS). A implantação dos conjuntos imobiliários ocorria nas áreas centrais e nos bairros da zona norte do município, a exemplo de Jaguaribe e dos Expedicionários. Com isso, até 1963, a cidade possuía cerca de 12 conjuntos populacionais e larga expansão para a região sudeste, que contempla atualmente o Conjunto Castelo Branco.

O processo de periferização do espaço, conduzido pelo fomento do Banco Nacional de Habitação-BNH, fora evidente na cidade em razão da aquisição pela população de baixo poder de 


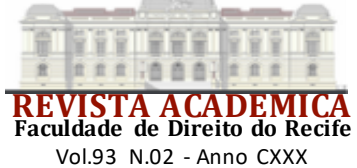

compra dos imóveis populares ali ofertados. Nesse período, a Companhia Estadual de Habitação Popular (CEHAP) já atuava na implantação dos principais conjuntos habitacionais, a exemplo dos bairros de Ernesto Geisel e de José Américo.

Cite-se que a alta da inflação - que será melhor trabalhada no tópico seguinte - promoveu um largo descontamento com a política implementada pelo BNH, mas sobretudo um processo de favelização em razão da inadimplência das dívidas referentes a imóveis. Ademais, a questão do déficit habitacional é latente à nível nacional, mas também no que se refere ao município em estudo:

\begin{abstract}
Em João Pessoa, o déficit habitacionalé de 23.000 unida des habita cionais, demonstrando como ainda é precária a atuação dos programas habitacionais desenvolvidos pelo poder público. Foram construídas mil habitações de interesse social na cidade, entre o ano de 2006 e 2011, para um total de 242.127 mil domicílios existentes, chegando a 3\%, produção totalinexpressiva e semelhante à produção habitacional no período dos IAPs e FCP (LEITE, 2011, p. 22)
\end{abstract}

Ao buscar uma solução para a problemática daqueda do mercado imobiliário, a Prefeitura Municipal de João Pessoa (PMJP) arquitetou o projeto "É pra morar", que tinha o objetivo de criar conjuntos habitacionais para famílias com renda mensal inferior a um salário mínimo. Com configuração parecida com o Programa "Minha Casa, Minha Vida(PMCMV), este programa tinha por objetivo atender a necessidade de moradia de trabalhadores que não possuíam local para ficar, os habitantes de zonas de risco e aqueles que moravam em condições precárias. Este ficou conhecido pela precariedade na construção dos imóveis, sendo posteriormente substituído pelo "Habitar Brasil" e "Morar Melhor", que ainda beneficiou cerca de 1168 famílias na cidade (BONATES, 2007, p. 72).

A partir das experiências anteriores e com o intuito de fortalecer o mercado imobiliário, houve a criação do Programa de Arrendamento Residencial (PAR) que garantiu um maior acesso de todas as camadas populacionais, abarcando aqueles que recebiam até seis salários mínimos. A CEHAP continuou como detentora pela produção dos conjuntos propostos pelo governo, facilitando o acesso ao crédito - às custas, notadamente, - do crescimento acelerado excludente e desigual da cidade. Cite-se:

Todo o percurso das habitações populares, na cidade de João Pessoa, revela segregação social imposta pelo Estado e pelo mercado imobiliário, cujo direito a uma mora dia digna permanece, ainda, com o passar dos anos, um direito restrito apenas a os cidadãos que podem pagar por ela. Percebemos que o modelo periférico de produção massiva de habitações socia is, produzidas a tualmente, assemelha -se a os grandes conjuntos popula res, produzidos na periferia pelo $\mathrm{BNH}$, um modelo de desenvolvimento urbano excludente e segregador, cujo produto "habitação" cresce, de forma acelerada, na periferia da nossa cidade, a tra vés da provisão esta tal de mora dias popula res (LEITE, 2011,p. 33).

Evidencia-se, nesse contexto, que a seleção de espaços além de reproduzir claros interesses mercantis, também contribui com o aprofundamento da periferização no que tange ao acesso equânime do uso da cidade. Ou seja, as unidades familiares menos abastadas, além de sofrerem com a precariedade dos serviços atinentes ao local em que vivem, também arcam com elevados custos de locomoção em razão da dificuldade de acesso aos bens e aos serviços urbanos.

Santos (2004, p. 42) corrobora com esse entendimento ao refletir acerca do valor do homem dentro do contexto de sua localização. A partir de conceitos como tempo, frequência e preço, pode-se delimitar o acesso a oportunidades que cada indivíduo possui e sua relação onde vive. Desse modo, justifica-se, portanto, o valor de um imóvel em condomínios de luxo na cidade de João Pessoa - PB, a exemplo do Condomínio Alphaville e a dissonância entre um imóvel adquirido no bairro do Ernani Sátiro, de população majoritariamente de menor poder aquisitivo, por exemplo. 


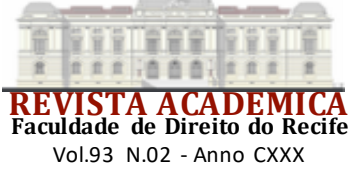

Ainda no que se refere ao acesso ao território, cite-se o Plano Diretor da cidade João Pessoa que dispõe, em seu art. $3^{\circ}$, ser um dos seus objetivos "a distribuição equânime dos custos e dos benefícios das obras e dos serviços de infra-estrutura urbana e a recuperação, para a coletividade, da valorização imobiliária dos investimentos públicos" (JOÃO PESSOA, 1990). Desse modo, é perceptível o intento do legislador em conferir o acesso à moradia de modo que agregue tanto os interesses comerciais - que não poderão ser negligenciados face aos interesses de capital - mas garantindo, sobretudo, o ideal de função social e de distribuição igualitária na ocupação do lugar.

Ponto importante é o fato de que a gestão urbana e a política habitacional tentam propiciar a oferta da moradia e o acesso à terra às camadas mais abastadas da população pensando, além das condições básicas de sobrevivência, a exemplo do saneamento básico, no acesso ao local de trabalho de modo a equilibrar o zoneamento da atividade produtiva. Nesse sentido, cabe citar o conceito que o plano diretor estabelece como função social:

\begin{abstract}
Art. 5. Para cumprir sua função social, a propriedade urbana deve satisfazer, simultaneamente, as seguintes condições: I - uso para atividades urbanas, em razão compatível com a capacidade da infra-estrutura instalada e do suprimento dos serviços públicos; II - a proveita mento e utilização integra dos à preservação da qualidade do meio a mbiente e do pa trimônio cultural, compatíveis com a segurança e saúde de seus usuários e das propriedades vizinhas.
\end{abstract}

Art. $6^{\circ}$. A proprieda de urbana cumpre sua função socialquan do o exercício dos direitos a ela inerentes se submete a os interesses coletivos (JOÃO PESSOA, 1990).

Portanto, a contradição na ocupação do território, no que tange às construções de projetos habitacionais, a exemplo do Programa "Minha Casa, Minha Vida"(PMCMV), não se trata de mera negligência em regulamentação, mas, sim, de sobreposição dos interesses de mercado que circundam tais programas. Saliente-se que a seletividade do espaço também se relaciona com a preponderância das grandes construtoras e a falta de interesse comercial em subsidiar a engenharia desses residenciais que, notadamente, não trazem o mesmo retorno financeiro que os arranha céus de luxo e condomínios fechados. Sendo a partir dessa conjuntura que a especulação imobiliária se sustenta, inclusive, aumentando os preços dos residenciais populares a fim de compensar os valores que são ofertados pelo subsídio governamental.

\title{
3 O PROGRAMA "MINHA CASA, MINHA VIDA E A PRODUÇÃO CAPITALISTA DO ESPAÇO
}

Ao refletir acerca da conjuntura econômica e social desde o período ditatorial, observase que, após o boom do crescimento, o Brasil sofreu grave recessão chegando a taxas negativas do Produto Interno Bruto (PIB). A crise dos anos 80 tem como uma das suas causas a Lei 4.591, promulgada no ano de 1964, que regulamentava o mercado imobiliário do país, preocupação que já era sinalizada pelas autoridades à época.

Uma série de medidas com o fim de atrair o investimento de capital privado no país e, consequentemente, controlar a inflação, foram tomad as pelos entes governamentais, a exemplo da instalação do Banco Nacional de Habitação-BNH, no ano de 1966, fruto também da Lei 4.591, tendo por finalidade financiar imóveis com a mediação governamental para todos os segmentos sociais. Do período da década de 1960 a de 1980, o BNH promoveu - por meio dos recursos do Fundo de Garantia por Tempo de Serviço (FGTS) e do Sistema Brasileiro de Poupança e Empréstimo (SBPE) - a construção de milhares de unidades de lotes habitacionais.

Entretanto, os grandes investimentos no ramo imobiliário não acompanharam o aumento da inflação, de modo que o BNH decreta falência e extinção (BANCO NACIONAL DE HABITAÇÃO-BNH, 2019) no ano de 1986. A alta das taxas de juros e o refinanciamento dos 
saldos devedores dos imóveis comprados no período tornou o setor imobiliário pouco atrativo para o investimento do capital das instituições privadas, de modo que, entre o período de 1990 a 2003 , não havia previsão nenhuma de mudança nesta conjuntura.

Nesta perspectiva, o governo, as financeiras e os construtores buscaram novos meios de oxigenar o setor, sendo, em 2004, aprovada a Lei 10.931 que implantou nos contratos imobiliários as regras da alienação fiduciária. Conforme o que dispõe o art. 29, II, da referida lei, os contratos firmados a longo prazo passaram a resguardar a construtora em caso de falência da empresa. Assim, fora possível alcançar, no ano de 2006, um PIB de 9,5\%, fomentado pelas políticas adotad as desde 2003 (LAGE, 2005).

Ainda no ano de 2004 fora criada a Política Nacional de Habitação (PNH), responsável pelo que se intitula de PlanHab, sendo este "um projeto de longo prazo, para o período de 2009 a 2023, instituído por meio da Lei 11.124/2005, que lançou o Sistema Nacional de Habitação de Interesse Social e criou o Fundo Nacional de Habitação de Interesse Social" (MOURA; FERREIRA, 2014,p. 67). Nesse contexto, tem-se evidente estratégia de redução das desigualdades regionais e um instrumento garantidor de condições dignas de moradia.

A partir disso, em 2007, tem-se a criação do Programa de Aceleração do Crescimento (PAC), que consiste em uma série de ações prioritárias que contribuiria com o crescimento do país em 4 anos (2007-2010). Dentre os blocos, tem-se o "Estímulo ao Crédito e ao Financiamento", no qual havia o intento de fomentar e atrair vultuosos montantes de crédito para investimento em infraestrutura e moradias, sobretudo, populares.

O programa Minha Casa, Minha Vida (PMCMV) surge no ano de 2009 com o intento de reduzir a taxa deficitária de moradias no país. À época, o governo pretendia criar 5,3 milhões moradias nas áreas urbanas, além de 750 mil no espaço rural (BRASIL, 2016). A Lei $\mathrm{n}^{\circ}$ $11.977 / 2009$, trouxe, em seu art. $1^{\circ}$, mecanismos para a criação, a aquisição ou a reformulação de imóveis de caráter urbano ou rural para grupos familiares com renda mensal de até $\mathrm{R} \$ 4.650,00$ (quatro mil, seiscentos e cinquenta reais). Vale ressaltar que, conforme orientação das cartilhas governamentais, grupo familiar é considerado uma unidade composta por indivíduos que contrib uem por meio de seu rendimento com a manutenção do coletivo (LEITE, 2011, p. 17). Assim, o programa:

\footnotetext{
(i) prioriza o atendimento à s família de mais baixa renda; (ii) estabelece um marco para a consolidação da política nacional de subsídios, confirmando a necessida de de subsídios públicos como um componente estruturante para a política habitacional do país; (iii) a umenta significativa mente os recursos governa menta is destina dos à área habitacional; e (iv) regula menta um conjunto de medidas jurídicas, urbanísticas, a mbientais e sociais que visam à regularização de assenta mentos informa is (BRASIL, 2019, p. 56).
}

De acordo com a "Cartilha do Minha Casa, Minha Vida" (PROGRAMA MINHA CASA MINHA VIDA, 2019), tal projeto seria, aprioristicamente, voltado para a construção de residenciais às famílias com renda mensal de até 3 salários mínimos. Contudo, em razão da crise financeira do ano de 2008 e com o intuito de aquecer ainda mais tal mercado, há a possibilidade de concessão de subsídios e descontos para os grupos familiares que recebem mais do que a primeira faixa de renda.

A versão I do projeto já contava com regras conhecidas, a exemplo de não ser proprietário de imóvel ou beneficiário de projeto com o mesmo cunho, além de só haver a cobrança efetiva do pagamento no momento de entrega das chaves; as casas eram registradas em nome da mulher, caso casado o comprador(a). Em se tratando das famílias com 3 a 10 salários mínimos, havia a possibilidade de construção da própria casa junto à Caixa Econômica Federal ou a elaboração dos projetos e aceite do referido banco no caso de proposta da construtora. Dentre os benefícios ofertados, há a possibilidade de financiamento de $100 \%$ do imóvel, prazo de até 30 anos para quitar o valor e juros condizentes com a renda mensal da pessoa ou família compradora, além da utilização dos recursos do Fundo Garantidor Habitacional (FGH).

No ano de 2011 foi lançado o Programa Minha Casa, Minha Vida-2 (PMCMV-2) com o 


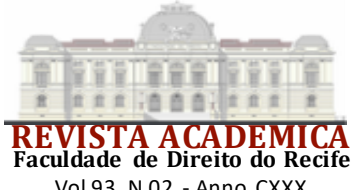

Vol.93 N.02 - Anno CXXX

intuito de duplicar a quantidade de moradias do escopo anterior. Houve significativa alteração nos padrões de concessão do crédito, a exemplo da limitação de 10 salários mínimos para o teto de R $\$$ 5.000,00 (cinco mil reais) e o limite de $\mathrm{R} \$ 1.600,00$ para as famílias de baixa renda, sendo esta a faixa I, conforme o enquadramento do Ministério das Cidades (GOVERNO, 2019).

Além dessas mudanças, a Lei 11.977/2009 também traz as alterações nos requisitos de contemplação dos municípios no programa, a exemplo de carecer de $70 \%$ da população no espaço urbano e de crescimento populacional entre os anos de 2000 e 2010 superior à taxa do Estado. Outro ponto pertinente refere-se ao fundo que gere cada faixa, sendo as famílias que possuem renda de até $\mathrm{R} \$ 3.100,00$ (três mil e cem reais) beneficiadas pelo FGTS e as que recebem até $\mathrm{R} \$$ $5.000,00$ (cinco mil reais) pelo FGH.

Em razão do recorte proposto por este artigo, analisaremos o PMCMV faixa 1, que tem por característica favorecer as unidades que possuem renda familiar de até $\mathrm{R} \$ 1.800,00$ (mil e oitocentos reais), não sendo enquadrado o bolsa família e o benefício de prestação continuada (BPC) neste cálculo. Além disso, não poderá o comprador(a) ser proprietário ou promitente de imóvel residencial e nem ter sido beneficiado anteriormente por qualquer programa social de habitação, conforme preceitua a Lei no 11.977/2009 que trata das regras do programa.

Quanto ao imóvel per si, este poderá ser casa ou apartamento com as dimensões de $35 \mathrm{~m}^{2}$ e $42 \mathrm{~m}^{2}$, devendo possuir cozinha, sala, banheiro, dois quartos e área externa. Em se tratando dos apartamentos, estes poderão ter quatro pavimentos com 16 (dezesseis) apartamentos ou 5 (cinco) pavimentos com 20 (vinte) apartamentos em cada bloco residencial, possuindo, evidentemente, infraestrutura de esgoto e energia elétrica, de acordo com as diretrizes da Portaria Ministério das Cidades no 114, de 09.02.2018 (MINISTÉRIO DAS CIDADES, 2019a) e Portaria Ministério das Cidades nº 269, de 24.03.2017 (MINISTÉRIO DAS CIDADES, 2019b).

Sabe-se que os protagonistas do Minha Casa, Minha Vida são as construtoras e a Caixa Econômica Federal. Tal centralidade permite que a localização dos imóveis seja, defato, escolhida por meio da lógica mercadológica, ocorrendo - como será visto a seguir - casas e apartamentos em terrenos baratos e periféricos, distantes, inclusive dos serviços essenciais de saúde e de educação dispostos como requisito do programa. Desse modo, a produção habitacional evidentemente não trabalha de maneira conjunta com a urbanização da cidade, contrariamente, se afasta dos projetos de ocupação justa e igualitária do espaço em favor dos interesses do capital imobiliário.

\section{A CRÍTICA DE MILTON SANTOS À RACIONALIDADE ESPACIAL DO MERCADO: A TEORIA DA RUGOSIDADE E AS POLÍTICAS PÚBLICAS CONTEMPORÂNEAS DE MORADIA}

Ao analisar a constituição das políticas de moradia é necessário considerar a relação espaço e tempo. Assim, a análise do espaço está centrada nas suas relações com o tempo, sendo este um conglomerado indissociável de objetos e de ações por meio de um fluxo dialético (SANTOS, 1986). As rugosidades são, portanto, o meio de compreender a influência dos tempos anteriormente materializados e como essa constituição interfere nas ações presentes em razão da complexidade da divisão do trabalho. Cita-se Santos (1986, p. 173):

As rugosidades são o espaço construído, o tempo histórico que se transformou em paisagem, incorporado a e espaço. As rugosidades nos oferecem, mesmo sem tradução imediata, restos de uma divisão de trabalho internacional, manifestada localmente por combinações particulares do ca pital, das técnicas e do trabalho utilizados.

A história de vida dos lugares mostra que os meios de produção estão inseridos numa ordem, numa sequência, que acaba por determinar um sentido àquele ao capital fixo (SANTOS, 2017, p. 157).

Essa sequência envolve os eventos, que são o acontecer, estão ligados às relações sociais. 


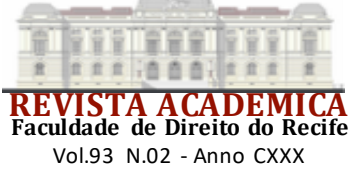

Existe uma interdependência entre os eventos de nível global e os de nível local. São frutos do mundo e do lugar, ao mesmo tempo, e atraem o meio de produção (tomado aqui como o objeto) que ele acaba de habitar (SANTOS, 2017, p. 163, 164).

Então, a região e o lugar não têm existência própria, não passam de abstrações se não forem considerados no todo mediante a divisão do trabalho e os acontecimentos. A região pode até ser considerada como um lugar, desde que a regra da unidade e da continuidade do acontecer histórico (como dito, o evento) se verifiquem. E o lugar pode, por sua vez, ser uma região (grandes cidades, por exemplo) (SANTOS, 2017, p. 165, 166).

A partir da relação dialética e sua criação de contradições, pode-se entender que as rugosidades são um processo "natural" da urbanização e da estratificação social, pois ao tempo em que tem-se a clara hierarquização das condições de vida nas cidades, de modo que não há a possibilidade de explicar tal processo por meio de uma abordagem geográfica meramente tecnicista ou tradicional, como suscitado por Santos (2004, p 82). Restringir a análise do processo social que permeia o movimento de ocupação das cidades está além da descrição de áreas ou de delimitação de períodos históricos. Essa análise possui reflexo no conceito de segregação, pois sabe-se que explicitamente o Estado não poderia separar grupos ou impedir seu acesso em determinadas localidades. Isto só poderia ocorrer a partir de um processo de articulação pelo qual os grupos são forçados a - involuntariamente - se agregarem em áreas definidas (MARCUSE, 2004, p. 24).

A seleção do território se dá em razão da dialética, mas no sentido de busca coletiva por meios de ocupação e de detenção do espaço e, também, das formas pelas quais tal empoderamento quanto ao espaço ocorre. Essa relação entre espaço e tempo está implícita em Karl Marx e Friedrich Engels, no livro "A id eologia alemã" (MARX; ENGELS, 2007), segund o o qual o cerne do debate está no embate histórico entre as teses materialistas e o idealismo filosófico - concepções que posteriormente consolid am a teoria marxista - pois tem-se a id eia de que a natureza reagiu ao tempo por meio de processos mecânicos, ou seja, desalinhados com as questões históricas que circundavam, sendo, portanto, uma lógica naturalizada e, de certa forma, silogística.

Santos $(2017$, p. 40) propôs a perspectiva do tempo espacial, de modo que o espaço determina os objetos segundo uma lógica. Esta lógica da instalação das coisas e da realização das ações é continuada pelo espaço. A síntese produzida no espaço não assegura uma harmonia no desenvolvimento espacial. Cada que se produz uma nova síntese se cria uma nova unidade. Existe, portanto, uma periodização da escala espacial do mundo, mas também a elaboração de outras periodizações, as escalas espaciais menores que agem, por sua vez, sobre escalas espaciais mais inferiores ainda, de maneira que tem-se as discussões sobre o tempo rápido e lento, por exemplo, no qual o primeiro teria enfoque nos processos históricos arraigados na estrutura social e o segundo nas situações cotidianas.

Neste contexto, Lefebvre (1999, p. 18) discute acerca dos fenômenos de implosãoexplosão e de urbanidade-ruralidade no contexto da urbanização. Ocorre que o processo de formação desses centros, fruto das instalações das coisas e das realizações das ações continuados no espaço, se dá de maneira não linear, assim, tem-se o deslocamento constante dos grupos sociais, seja para os centros mais abastados da cidade ou para as periferias residenciais, complexificando o movimento de apropriação desses espaços. Santos (2004, p. 33) reforça:

Quanto mais o processo produtivo é complexo, mais as forças materiais e intelectuais necessárias a o trabalho são desenvolvidas, e maiores são as cidades. Mas a proximidade física não elimina o distanciamento social, nem tampouco facilita os contatos humanos não-funcionais. A proximidade física é indispensável à reprodução da estrutura social. A crescente separação entre classes agrava a distância social. Os homens vivem cada vez mais a montoados la do a lado em aglomerações monstruosas, mas estão isolados uns dos outros.

Neste sentido, os eventos (o acontecer histórico) podem ser homólogos ou complementares. Homólogos correspondem às áreas agrícolas ou urbanas, que se modernizam 


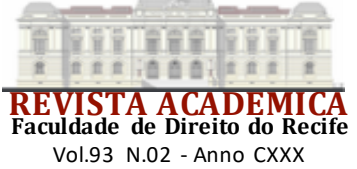

mediante uma informação especializada, gerando continuid ades funcionais que dão os contornos da área assim definida (SANTOS, 2017, p. 166). Complementares quando envolvem cidade e campo ou entre cidades, consequência da proximidade geográfica e das necessidades da produção. E ainda tem o hierárquico, resultado da racionalização das atividades, que se faz sob um comando, uma organização, tendentes à concentração (SANTOS, 2017, p. 166-167). A rugosidade envolve uma relação entre esses eventos.

A rugosidade, portanto, se situa no contexto de consolidação do capital no espaço a ser observado. No caso do Minha Casa, Minha Vida, a seleção de espaços para construção dos residenciais sorteáveis em bairros periféricos é reflexo da construção do tempo na região analisada e da produção de desigualdade que se evidencia. Desse modo, a hierarquização separa os interesses de cada grupo que envolve tal processo histórico e segrega os espaços de acordo com as características de cad a grupo, sendo esta mensurada a partir da divisão do trabalho e da delimitação do poder político. Tal conceito está relacionado com a compreensão de Milton Santos no que denomina de "totalidade" da problemática do espaço geográfico, ultrapassando a mera análise tecnicista que promovia a geografia, mas entendendo que a territorialidade é perpassada por um emaranhado de situações políticas, sociais e econômicas que influenciam em sua conformação.

A noção de totalidade é uma das mais fecundas que a filosofia clássica nos legou, constituindo em elemento fundamental para o conhecimento e análise da realidade. Segundo essa ideia, todas as coisas presentes no universo formam uma unidade. Cada coisa nada mais é que parte da unidade, do todo, mas a totalid ade é uma simples soma das partes. As partes formam a totalidade não bastam para explicá-la. Ao contrário, é a totalidade que explica as partes (SANTOS, 2004, p. $115)$.

Tal perspectiva também possui influência da posição do Estado como principal mediad or dessas relações. A produção e a reprodução do capital também norteiam a ação dos agentes públicos e políticos no processo de segregação do espaço. Em momentos de conflito, notadamente, os interesses de classe se sobrepõem diante das necessidades materiais das classes exploradas, de modo que a territorialidade e o conflito pelas relações de poder estabelecidas são constantemente confrontadas, pois não basta a reivindicação do espaço, mas também o modo pelo qual este é utilizado, seja para fins de reprodução da ótica financeira ou como meio de subsistência. Cite-se Harvey (1992, p. 209-210):

(...) a progressiva monetização das relações na vida social transforma as qualidades do tempo e do espaço. A definição de "um tempo e um lugar para tudo" muda necessariamente, formando uma nova estrutura de promoção de novos tipos de relações sociais. (...) O capitalismo, tem se caracterizado devido a isso, por contínuos esforços redução do tempo do giro, acelerando assim processos sociais, a o mesmo tempo em que diminui os horizontes tempora is das tomadas de decisões significativa s. (...) O efeito geral é, portanto, colocar no centro da modernidade capitalista a aceleração do ritmo dos processos econômicos e por conseqüência, da vida social. Mas essa tendência é descontínua, pontuada por crises periódicas, porque os investimentos fixos em insta lações e equipamentos, bem como em formas organizacionais e habilidades de trabalho, não podem ser modificados com facilidade.

Tem-se, portanto, o conflito entre a construção do imaginário da casa própria, que historicamente é um sonho criado a partir da disputa entre classes, e a forma que se dá a seletividade dos grupos que efetivamente acessam este "imaginário". É necessário pontuar que a ocupação de certas localidades demanda não somente a mera vivência, mas, sobretudo, sobrevivência, ao pensar sobre as necessidades de alimentação, de saúde, de transporte e de saneamento básico, por exemplo. É nesse contexto que se pode entender o processo de urbanização, a partir do viés do status social, ao pensar nos condomínios luxuosos e nas casas de veraneio ou na precariedade e na espoliação decorrente da ocupação em bairros periféricos ou comunidades.

Ainda no contexto do discurso que envolve a moradia própria, sabe-se que o sentimento de pertencimento também perpassa essa questão. É possível apreender que o local onde o indivíduo 


\begin{tabular}{|l|l|}
\hline Residencial Vitória & Geisel \\
\hline Residencial Villa Sanhauá & Varadouro \\
\hline Residencial Vale das Palmeiras & Cristo \\
\hline Residencial Vieira Diniz & Jardim Veneza \\
\hline Residencial Jardim Veneza & Jardim Veneza \\
\hline Residencial Jardim das Colinas & Gramame \\
\hline Residencial Manacá & Paratibe \\
\hline Residencial Irmã Dulce & Colinas do Sul \\
\hline Residencial Gervásio Maia & Colinas do Sul \\
\hline Residencial Luzia do Taipa & Costa e Silva \\
\hline Residencial Anaide Beyriz & Distrito das Indústrias \\
\hline Residencial Alvorada & Alto do Céu \\
\hline Residencial Monte Cassino & Jaguaribe \\
\hline Residencial Val Paraíso & Bessa \\
\hline
\end{tabular}

Fonte: (RICARDO, 2019).

A priori, é importante analisar o contexto de criação destes residenciais. Um exemplo desse recorte está na vulnerabilidade espacial a qual boa parte dos moradores das comunidades e dos bairros mencionados se encontrava antes da construção das casas. Foi possível observar ao longo desse estudo que existe, de fato, uma pressão que interfere diretamente na alocação dos recursos para a fundação destes residenciais. Não se trata, portanto, de mero intento em diminuir a problemática da falta de moradia, mas sim conter o impacto causado pela sangria social, pois os indivíduos que ocupam esses espaços vêm de um histórico da precariedade ou falta de moradia, condições de saúde, de trabalho, de saneamento e de acesso aos espaços da cidade. Cita-se:

Esta manhã foihistórica para a cidade de João Pessoa e, principalmente, para as famílias do São José, que receberam as chaves de seus apartamentos. Vivendo em uma região de extrema vulnerabilidade social e onde os riscos de alagamentos e inundações eram constantes, estas pessoas estão sendo beneficia das pelo maior programa habitacional da história de João Pessoa, que chega hoje à marca de 7.153 casas já entregues desde janeiro de 2013. "Este é mais um desafio histórico de João Pessoa que nós tivemos a cora gem de enfrentar, buscar a solução e chegar a este momento importante de conclusão com a entrega dos 336 apartamentos, dois meses depois de já ter entregado a urbanização do bairro. Estamos abrindo o São José, mudando a cara do bairro e, mais do que isso, transformando para muito melhor a vida de tantas pessoas", a firmou o prefeito Luciano Cartaxo (LUCIANO, 2019).

É evidente que nas situações em que não existe o acesso a tais políticas de governo, temse a dissonância entre a urbanização e a modernização do espaço, que propicia a desigualdade no acesso, de modo que a única alternativa para esse grupo é construir suas residências em loteamentos clandestinos, vilas, alagados, etc. A Organização das Nações Unidas (ONU) intitula esse tipo de ocupação de "assentamento precário", sendo aquele que não é reconhecido pelo poder público e oferece condições inadequadas de serviços básicos e habitação (QUEIROZ FILHO, 


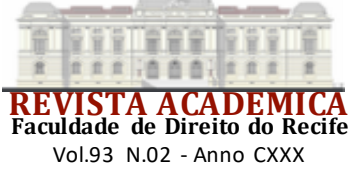

2019, p. 341). O Plano Diretor do município dispõe também, em seu art. 57, parágrafo único, que "déficit habitacional quantitativo é aquele decorrente da inacessibilidade pura e simples do indivíduo ou das famílias residentes à casa própria e que esteja morando em imóvel alugado ou em qualquer forma de locação precária, além daquelas famílias conviventes num único domicílio" (JOÃO PESSOA, 1990). Assim, a política habitacional do município segue um conjunto de diretrizes transcritas abaixo:

\begin{abstract}
Art. 58. A política habitacional da Cidade de João Pessoa será implantada a partir das seguintes diretrizes:

I - elaboração de um plano de reassentamento das populações localizadas em áreas de risco, com rigorosa e imediata destinação de uso das áreas desocupadas para evitar novos assentamentos;

II - urbanização e regularização fundiária das favelas e a ssentamentos de baixa renda, com prioridade para áreas ocupadas há mais de 02 (dois) anos, a partir da da ta de publicação desta Lei;

III - adoção de programas de incremento a oferta de lotes urbanizados e de financiamento de moradias populares, com prioridade para autoconstrução individual ou comunitána e para a participação da pequena empresa local;

IV - criação,por lei especial, do Fundo Municipal de Fomento a Habitação, para captado de recursos destinados à produção e melhoria de habitação, para a população de baixa renda.
\end{abstract}

Denota-se, portanto, que o embasamento que norteia a construção dos habitacionais está, justamente, no argumento da precariedade das condições de vida. Não há, nesse ponto, críticas, mas é pertinente questionar de que modo as condições se estabelecem após a realocação desses indivíduos nos residenciais sorteados pelo governo. Ainda no que tange a tabela, sabe-se que os bairros escolhidos, de fato, estão nas periferias e nas comunidades do Oeste e do Sul do município de João Pessoa-PB, confirmando a seletividade desses espaços e a permanência desses grupos nas localidades precárias onde sempre habitaram.

Uma localidade destoante dessa realidade, mas que carece de melhor análise é o Residencial Val Paraíso no bairro do Bessa. Sabe-se que tal localidade é conhecida por alocar boa parte da população de alta e altíssima renda do município. Uma notícia veiculad a na data de 12 de agosto de 2009, no site da Prefeitura de João Pessoa, menciona o fato de a Superintendência de Transportes e Trânsito (STTrans) ter transferido e aumentado a rota de ônibus 510 - que linha o bairro de Tambaú ao Bessa - em razão da solicitação da comunidade do Val Paraíso, por conta da distância no deslocamento para o local (STTRANS, 2019). A partir desse caso fático, é possível compreender o fenômeno que circunda a questão do Minha Casa, Minha Vida e a segregação esmaecida nesse processo, pois na situação prática em que há a disposição de um espaço territorial de melhor qualidade, as condições de vida da população restam por não comportar o padrão de vida que o local impõe, confirmando a ideia de Santos (2004, p. 63) de que o espaço geográfico é um sistema contraditório que passeia entre um conjunto de objetos e ações indissociáveis.

Confirma-se, portanto, que a conjunção do aspecto do pertencimento ao espaço e da promoção de acesso mediada pelo Estado garante ao indivíduo de baixa renda a ideia de empoderamento. Contudo, ressalte-se que o contexto de criação desses residenciais é permeado pela separação desses grupos dos espaços que têm maior acesso do mercado. Visto isso, não é possível analisar o Programa Minha Casa, Minha Vida sem o recorte social que este promove, pois não é necessário largo estudo empírico para reconhecer as diferenças entre os grupos que estão alocad os nesses residenciais.

\title{
6 CONCLUSÃO
}

Conforme vimos ao longo deste trabalho, a problemática da moradia e a (re)produção do espaço urbanístico na cidade de João Pessoa-PB sofre influência direta do movimento nacional de espoliação urbana e periferização de certos segmentos sociais em locais pré-estabelecidos pela 
ótica de mercado. O território configura-se, nesse contexto, como ponto fundamental imerso nas contradições que as políticas habitacionais promovidas ao longo dos anos.

Em se tratando do Programa Minha Casa, Minha Vida "faixa I", foi possível compreender o duplo processo de atendimento aos interesses mercadológicos e o estanque da sangria social que envolve a ocupação de determinados indivíduos em segmentos territoriais que não os comportam em razão da seletividade do espaço. É a partir desse fenômeno que tem-se a mera naturalização da facilidade de acesso dos grupos mais abastados da sociedade na região norte e no litoral do município, em detrimento do segmento subalternizado que ocupa as áreas periféricas centrais e as novas ocupações, a exemplo da comunidade Paratibe ou Nova Mangabeira.

O sorteio das casas da faixa I, do citado programa habitacional promoveu, de fato, o avanço e empoderamento desses cidadãos que sempre estiveram à margem de qualquer acesso à moradia digna. Mas é importante pontuar que a noção de mercadoria também está inserta nesse contexto, em função da hierarquização e da estabilização das condições de vida desse segmento. Promover o acesso aos residenciais do referido programa, além de mitigar a problemática da moradia, que é direito fund amental garantid o na Constituição Federal de 1988, mantém esse grupo longe de ocupar os locais que são mais rentáveis às grandes construtoras e aos bairros de classe média e alta do município pessoense.

Confirma-se, portanto, a hipótese acerca dahierarquização e da seleção do espaço em que tais grupos ocupam, pois, a listagem de condomínios construídos pelo município com os fundos do programa federal mantém o padrão dos espaços ocupados e reflete a tendência em alargar os bairros novos que foram "criados" nesse intento. Ademais, o único caso em que o residencial está localizado em bairro nobre da cidade, que é o caso do Bessa, é evidente a dificuldade de locomoção e de ocupação de todos os espaços que o entorno do local pode oferecer.

\section{REFERÊNCIAS}

BANCO NACIONAL DE HABITAÇÃO-BNH (Brasil). Disponível em: http://www.fgv.br/cpdoc/acervo/dicionarios/verbete-tematico/banco-nacional-da-habitacao-bnh. Acesso em: 05 set. 2019.

BARBOSA, Adauto Gomes. Produção do espaço e transformações urbanas no litoral sul de João Pessoa - PB. 2005. Dissertação (Mestrado) - Universidade Federal do Rio Grande do Norte, Natal, 2005.

BONATES, Mariana Fialho. Ideologia da casa própria... sem casa própria. O programa de arrendamento residencial na cidade de João Pessoa - PB. 2007. Dissertação (Mestrado em Arquitetura e Urbanismo) - Universidade Federal do Rio Grande do Norte, Natal, 2007.

BRAGA, Maria do Carmo de Albuquerque. A gestão do patrimônio imobiliário da União e a dinâmica espacial da Região Metropolitana do Recife. Tese (Doutorado) - Universidade Federal de Pernambuco, Recife, 2006.

BRAGA, Maria do Carmo de Albuquerque. O Patrimônio Imobiliário Público Vila Naval em Recife/PE. Continuação de privilégios e interesses particulares sobre os coletivos? Revista Movimentos Sociais e Dinâmicas Espaciais, Recife, v. 05, n. 02, 2016.

BRASIL. Lei $n^{o}$ 11.977, de 7 de julho de 2009. Dispõe sobre o Programa Minha Casa, Minha Vida-PMCMV e a regularização fundiária de assentamentos localizados em áreas urbanas. Disponível em: http://www.planalto.gov.br/ccivil_03/_ato2007-2010/2009/lei/111977.htm. Acesso: 26 out. 2019. 
BRASIL. Ministério das Cidades. Plano Nacional de Habitação. Disponível em: http://www.urbanismo.mppr.mp.br/arquivos/File/Habitacao/Material_de_Apoio/PLANONACIO NALDEHABITAO.pdf. Acesso em: 27 set. 2019a.

BRASIL. Ministério do Desenvolvimento. Programa Minha Casa, Minha Vida Programa Nacional de Habitação Urbana. 2009. Disponível em:

http://www.planejamento.gov.br/assuntos/investimento-e-pac/publicacoes-nacionais/cartilhaminha-casa-minha-vida.pdf/@@download/file/Cartilha\%20-

\%20Minha\%20Casa\%20Minha\%20Vida.pdf. Acesso em: 26 set. $2019 \mathrm{~b}$.

BRASIL. Resultados do Programa Minha Casa, Minha Vida (2016). Disponível em: http://www.minhacasaminhavida.gov.br/. Acesso em: 26 out. 2019.

DALLARI, Adilson Abreu; FERRAZ, Sérgio (org.). Estatuto da Cidade: comentários à Lei Federal 10.257/2001. 2. ed. São Paulo: Malheiros Editores, 2006.

DAMATTA, Roberto. A casa \& a rua: espaço, cidadania, mulher e morte no Brasil. 5. ed. Rio de Janeiro: Rocco, 1997.

ENGELS, Friedrich. Contribuição ao problema da habitação. In: MARX, Karl; ENGELS, Friedrich. Obras escolhidas. São Paulo: Alfa-Ômega, [1986]. p. 105-182.

ESCOLINHA de futebol do residencial vista alegre tem aula inaugural neste sábado. Disponível em: http://www.joaopessoa.pb.gov.br/escolinha-de-futebol-do-residencial-vista-alegre-tem-aulainaugural-neste-sabado/. Acesso: 26 out. 2019.

GOVERNO Federal libera meio bilhão para o Programa Minha Casa, Minha Vida. Disponível em: http://www.cidades.gov.br/ultimas-noticias/12264-governo-federal-libera-meio-bilhao-parao-programa-minha-casa-minha-vida. Acesso em: 12 jun. 2019.

HARVEY, David. A produção capitalista do espaço. 2. ed. São Paulo: Annablume, 2006.

HARVEY, David. Cidades rebeldes: do direito à cidade à revolução urbana. São Paulo: Martins Fontes, 2014.

HARVEY, David. Condição pós-moderna. 16 ed. Loyola, São Paulo, 1992.

JOÃO PESSOA. Lei orgânica do município de João Pessoa/PB. 1990. Disponível em: https://leismunicipais.com.br/lei-organica-joao-pessoa-pb. Acesso em: 31 ago. 2018.

JOÃO PESSOA. Plano diretor da cidade de João Pessoa/PB. 1994. Disponível em: https://leismunicipais.com.br/plano-diretor-joao-pessoa-pb. Acesso em: 31 ago. 2018.

LAGE, Janaina. PIB cresce 5,2\% em 2004, o melhor desempenho desde 1994, diz IBGE. Folha de São Paulo, Folha Online, São Paulo, 01 mar. 2005 Disponível em:

https://www 1.folha.uol.com.br/folha/dinheiro/ult91u93876.shtml. Acesso: 26 out. 2019.

LEFEBVRE, Henri. $O$ direito à cidade. 5. ed. São Paulo: Centauro, 2008.

LEFEBVRE, Henry. A revolução urbana. Belo Horizonte: Ed. UFMG, 1999.

LEITE, Amanda Pessoa de Araujo. A produção de habitações populares no espaço periurbano 
da cidade de João Pessoa - PB (2006-2011): o conjunto habitacional Gervásio Maia. 2011. Dissertação (Mestrado) - Universidade Federal da Paraíba, João Pessoa, 2011. Disponível em: https://repositorio.ufpb.br/jspui/bitstream/tede/292/1/arquivototal.pdf. Acesso em: 12 jun. 2019.

LUCIANO Cartaxo entrega chaves de 336 apartamentos no Residencial São José e oferece lar digno a mais de 1.300 pessoas que viviam em áreas de risco. Disponível em: http://www.joaopessoa.pb.gov.br/luciano-cartaxo-entrega-chaves-de-336-apartamentos-noresidencial-sao-jose-e-oferece-lar-digno-a-mais-de-1-300-pessoas-que-viviam-em-areas-derisco/. Acesso: 13 jul. 2019.

MAIA, Doralice Sátyro. A periferização e a fragmentação da cidade: loteamentos fechados, conjuntos habitacionais populares e loteamentos irregulares na cidade de Campina Grande-PB, Brasil. 2010. Disponível em: http://www.ub.edu/geocrit/sn/sn-331/sn-331-80.htm. Acesso em: 31 ago. 2018.

MARCUSE, Peter. Enclaves, sim; guetos, não: a segregação e o estado. In: ESPAÇO e Debates, São Paulo, v. 24, n. 45, jan./jul. 2004.

MARX, Karl; ENGELS, Friedrich. A ideologia alemã: crítica da mais recente filosofia alemã em seus representantes Feurbach, B. Bauer e Stirner, e do socialismo alemão em seus diferentes profetas. São Paulo: Boitempo, 2007.

MEDEIROS, Sara Raquel Fernandes Queiroz de. A casa própria: sonho ou realidade?: um olhar sobre os conjuntos habitacionais em Natal. 2007. Dissertação (Mestrado) - Universidade Federal do Rio Grande do Norte, Natal, 2007. Disponível em:

ftp://ftp.ufrn.br/pub/biblioteca/ext/bdtd/SaraRFQM.pdf. Acesso em: 10 jul. 2019.

MINISTÉRIO DAS CIDADES. Portaria $n^{\circ}$ 114, de 09 de fevereiro de 2018. Disponível em: http://www.editoramagister.com/legis_27612586_PORTARIA_N_114_DE_9_DE_FEVEREIR O_2018.aspx. Acesso em: 27 set. 2019a.

MINISTÉRIO DAS CIDADES. Portaria $n^{\circ}$ 269, de 22 de março de 2017. Disponível em: http://www.editoramagister.com/legis_27349742_PORTARIA_N_269_DE_22_DE_MARCO_D E_2017.aspx. Acesso em: 27 set. 2019b.

MOURA, Gerusa Gonçalves; FERREIRA, Leilaine de Fátima. Plano nacional de habitação: atual cenário do programa minha casa minha vida. 2014. Disponível em:

https://period icos.furg.br/cnau/article/download/4832/3126. Acesso em: 26 set. 2019.

PREFEITURA MUNICIPAL DE JOÃO PESSOA. Topografia social da cidade de João Pessoa. Disponível em: http://www.cchla.ufpb.br/nepps/wp-

content/uploads/2017/05/TOPOGRAFIA_SOCIAL-JP.pdf. Acesso em 31 ago. 2018.

PROGRAMA MINHA CASA MINHA VIDA. Disponível em:

https://www.ipea.gov.br/portal/images/stories/PDFs/131114_ifh_castilha_minha_casa.pdf.

Acesso: 26 out. 2019.

QUEIROZ FILHO, Alfredo Pereira de. As definições de assentamentos precários e favelas e suas implicações nos dados populacionais: abord agem da análise de conteúdo. 2015. Disponível em: http://www.scielo.br/pdf/urbe/v7n3/2175-3369-urbe-2175-3369007003AO03.pdf. Acesso em: 27 set. 2019. 
RIBEIRO, Luiz César de Queiroz \& SANTOS JR, Orlando Alves dos (org.). Globalização, fragmentação e reforma urbana: o futuro das cidades brasileiras na crise. Rio de Janeiro: Civilização Brasileira, 1994.

RICARDO assina $1^{\circ}$ contrato do Minha Casa, Minha Vida na PB. Disponível em: http://www.joaopessoa.pb.gov.br/ricardo-assina-1\%c2\%b0-contrato-dominha-casa-minha-vidana-pb/. Acesso em: 12 jul. 2019.

ROLNIK, Raquel (org.). Estatuto da Cidade: Guia para implementação pelos municípios e cidadãos: Lei $\mathrm{n}^{\circ}$ 10.257, de 10 de julho de 2001, que estabelece diretrizes gerais da política urbana. 2. ed. Brasília: Câmara dos Deputados, Coordenação de Publicações, 2002.

ROLNIK, Raquel (org.). Guerra dos Lugares: a colonização da terra e da moradia na era das finanças. São Paulo: Boitempo, 2015.

ROLNIK, Raquel; SANTORO, Paula. Zonas Especiais de Interesse Social (ZEIS) em Cidades Brasileiras: Trajetória Recente de Implementação de um Instrumento de Política Fundiária. Lincoln Institute of Land Policy, 2014. Disponível em: https://www.lincolninst.edu/publications. Acesso em: 10 de jan. 2017.

ROSSBACH, Ana Claudia (org.). Estatuto da Cidade: a velha e a nova agenda urbana: uma análise de 15 anos de lei. São Paulo: Cities Alliance, 2016.

SANTOS, Milton. A Natureza do espaço: espaço e tempo, razão e emoção. 4. ed. São Paulo: Edusp, 2017.

SANTOS, Milton. A urbanização brasileira. São Paulo: Hucitec, 1993.

SANTOS, Milton. Pensando o espaço do homem. São Paulo: Edusp, 2004.

SANTOS, Milton. Por uma geografia nova: da crítica da geografia a uma geografia crítica. 3. ed. São Paulo: HUCITEC, 1986.

SILVEIRA, J. A. R. Produção e apropriação do espaço nas fronteiras intraurbanas de cidade de porte médio: um estudo sobre a dinâmica da ocupação e uso do solo nas bordas da cidade de João Pessoa - PB. Projeto de Pesquisa. Universidade Federal da Paraíba. Centro de Tecnologia. Laboratório de Ambiente Urbano e Edificado (LAURBE), 2010.

STTRANS muda terminal da linha 501 para residencial Val Paraiso. Disponível em: http://www.joaopessoa.pb.gov.br/sttrans-muda-terminal-da-linha501-para-residencial-valparaiso/. Acesso em: 13 jul. 2019.

UNIVERSIDADE FEDERAL DA PARAÍBA. Projeto de pesquisa. O direito à cidade a partir da crise do capitalismo e o seu impacto na discussão do processo de formação de gestores $e$ planejadores urbanos. Disponível em:

https://sigaa.ufpb.br/sigaa/public/pesquisa/consulta_projetos.jsf. Acesso em: 04 abr. 2019.

VALE, Kátia Cristina do; GARCIA, Maria Franco. A dinâmica geográfica da luta pela moradia em João Pessoa no último decênio (1998-2008): dez anos de transformações (ou) mudanças e permanências. 2008. Disponível em: http://www.ub.edu/geocrit/-xcol/276.htm. Acesso em: 31 
REVISTA ACADEMICA
Faculdade de Direito do Recife

Vol.93 N.02 - Anno CXXX

ago. 2018 .

MAIA, Fernando Joaquim Ferreira" COSTA, Klivia Larissa Cardoso da DIREITO E ESPACO NO PROGRAMA "MINHA CASA, MINHA VIDA" EM JOÃO PESSOA. Revista Acadêmica da Faculdade de Direito do Recife - ISSN: 2448-2307, v.93, n.2, p. 116-132 Out. 2021. ISSN 2448-2307. Disponível em: https://periodicos.ufpe.br/revistas/ACADEMICA/article/view/250358> 